\title{
The Ethics of Arguing
}

\author{
Hugh Breakey ${ }^{1}$
}

\begin{abstract}
Contemporary argumentation theory has developed an impressive array of norms, goals and virtues applicable to ideal argument. But what is the moral status of these prescriptions? Is an interlocutor who fails to live up to these norms guilty of a moral failing as well as an epistemic or cognitive error? If so, why? In answering these questions, I argue that deliberation's epistemic and cognitive goods attach to important ethical goods, and that respect for others' rationality, the ethics of joint action, and the importance of consensus join forces with these goods to provide strong reasons for cleaving to high standards of argument. I sketch an illustrative continuum of argument practices of different deliberative-cum-ethical standards, and consider how one should ethically respond when faced with an interlocutor employing less than ideal standards.
\end{abstract}

\section{Keywords}

argumentation ethics; argument practices; deliberative virtue; ethics of belief; standards of argument; Immanuel Kant.

\footnotetext{
${ }^{1}$ h.breakey@griffith.edu.au. Institute for Ethics, Governance \& Law, Law Futures Centre, Griffith University, Australia; ORCID ID: 0000-0002-5170-2091. The Version of Record of this manuscript has been published as Breakey, Hugh. 2020. The Ethics of Arguing. Inquiry, and is available at https://www.tandfonline.com/doi/abs/10.1080/0020174X.2019.1637776
} 


\section{Introduction}

On an intuitive level, we all know perfectly well that argument is a morally loaded activity. Many of us have enjoyed the sense of respect and recognition that comes with being truly heard and understood, and seeing one's ideas at work in changing someone's mind. Some of us may even have felt that profound sense of shared creation that the most thoughtful and intimate deliberations can instil. And most of us - perhaps here I can even say all of uswould have felt the sting of disrespect when we are mistreated in argument, our contribution ignored or caricatured, a victim of careless disregard or win-at-all-costs point-scoring. And when we suffer that sting, it does not seem like our interlocutor made a purely logical or cognitive mistake, or merely breached an instrumental norm whose purpose one might or might not share. Rather, it feels as if something genuinely wrongful has occurred (Schreier et al. 1995). These intuitions about moral significance appear in contemporary argumentation theory, which notes en passant the intertwining of ethical, epistemic and cognitive goods (Eemeren and Grootendorst 2003, 22, 188; Walton 1989, 175).

What, if anything, vindicates those moral evaluations, intuitions and emotions?

In this paper, I advance a multipronged argument for the conclusion that the norms of argument have a strong ethical valence. I begin in Section 1 by drawing on existing work on deliberative virtues and argumentation theory to define an illustrative high-standards argument-practice. This practice — 'shared deliberation' — is delineated in terms of its shared goals and the norms that deliver those goals. Section 2 observes some basic moral issues surrounding argument, before Section 3 outlines the epistemic and cognitive goods we can expect to garner from shared deliberation. Section 4 considers ethical reasons we can have for pursuing those epistemic and cognitive goods, and for respecting others' pursuit of them. Section 5 augments these reasons with a special source of deliberative ethics: the way deliberative norms display respect for others' rationality, noting Kantian reasons why this is 
morally significant. Section 6 takes a different tack, building on argument's nature as a genuinely shared activity, and considers what ethical significance this collectivity adds. Section 7 considers the moral significance of the pursuit of consensus and conflict resolution between deliberators. Together, these sections establish we have strong reasons for obeying high-standards argument norms. But how do those reasons fare in the less than ideal reality in which we currently live, where there are many lower-standards types of argument-practice that others may adopt when deliberating with us? Section 8 provides a sketch of this reality, describing a continuum of argument-practices of varying ethical and epistemic standards. Drawing on the reasons adduced in Sections 4-7, I argue in Section 9 that we have surprisingly strong moral reasons to hold to high deliberative standards even when we feel our opponent is failing to do so.

Before beginning, some scope clarifications.

First, this paper explores the ethics of how to behave while engaged in argument - the 'jus in bello' of argument, as it were. ${ }^{2}$ I will, so far as possible, avoid broaching the related (jus ad bellum) questions of when it is morally necessary to initiate, join, demand, remain in or leave an argument.

Second, I will bracket special cases where the norms of argument are set by explicit rules and prior agreements, consented to by all deliberators and known to their audiences. For example, attorneys presenting their closing arguments in an adversarial justice system are bound by their special roles in the larger institutional framework. These roles rightly impact upon their ethical obligations as they argue.

\footnotetext{
${ }^{2}$ I thank an anonymous reviewer for suggesting this figure.
} 
Third, I focus exclusively on the interpersonal ethics of arguing. In contrast, political theories of deliberative democracy aim to show how systemic, representative and comprehensive regimes of high-standards deliberation can provide legitimacy for political regimes, constitutional structures and normative standards (Joshua Cohen 2004; Rawls 2005). No doubt such arguments provide strong ethical reasons for citizens to engage in everyday highquality deliberations (Umphres 2018). And no doubt other civic-political arguments could be made, highlighting the importance of inclusive deliberation for real-world policy governance (Cadman 2011), extolling one's role in political discourse as a civic virtue (Rorty 2011), or playing one's part in a community-wide social epistemology (Mill 1859/2003). In what follows I set aside all of these (comparatively well-trammelled) lines of justification for highstandards deliberation. Instead, I focus purely on moral rather than political goods, interpersonal rather than civic obligations. Why-irrespective of any larger political or civic goods - would the standards of argument be ethically significant?

\section{Shared Deliberation defined}

Human beings being what they are, for any collective enterprise to reliably achieve its goals, certain norms, roles and virtues need to be performed. 'Shared deliberation' constitutes a collective practice designed to rationally resolve a disagreement on its merits. ${ }^{3}$ Deliberators aim to develop inter-subjectively shared reasons that provide logical support for or against their evolving positions, in order to facilitate joint understanding and agreement on the topic. This practice captures several familiar types of argument-including the persuasion dialogue

\footnotetext{
${ }^{3}$ I will generally speak as if the deliberation is occurring between two or more face-to-face interlocutors interacting in real time. However, most of what follows will also apply to more mediated contexts, such as online debates through social media platforms, or the iterated deliberation of academics penning articles responding to each other.
} 
(where deliberators try to use the commitments of their opponents to vindicate the truth of their thesis), the inquiry (where two deliberators with different views try to establish an answer to a shared conundrum) and collective decision-making (where deliberators provide reasons to secure consensus on a position, policy or action). However, there are argument types to which the following analysis does not apply_including the important practices of bargaining and negotiation (Walton 1989).

Resolving a disagreement on its merits requires compliance with an array of procedural and substantive norms. The following account of shared deliberation's norms draws on major philosophical theories of idealised argumentation and deliberative virtue, from the classical (Bentley 2005; Plato 1997 (380BC); White 1983) to the modern (Aberdein 2010; Daniel Cohen 2009; Daniel Cohen and Miller 2016; Eemeren and Grootendorst 2003; Schreier et al. 1995; Thorson 2016), as well as theories of dialogue and ethics of communication (Johannesen 1971; Keller and Brown 1968).

Shared deliberation involves the following constitutive norms:

Mutual respect and equal standing: The same reciprocal rules apply to all deliberators, and no deliberator commands intrinsic authority in the argument (though deliberators may present evidence for their special expertise, relevant experience or unique insight).

Good faith speech: Deliberators say what they believe - unless they explicitly flag otherwise, such as by conceding a point for the sake of argument or playing 'devil's advocate' to test a line of reasoning. Frankness is also valued; deliberators acknowledge their deeper reasons and convictions.

Open-mindedness: All opposing viewpoints may be aired and must be taken seriously. Deliberators must not only listen to, and genuinely consider, arguments against their 
position, but should actively seek out counter-arguments, contrary evidence and alternative positions. Deliberators remain fallibilistic in the sense of being open to admitting errors or ignorance, and - at least in principle — to changing their minds. Forgoing ulterior tactics: Aiming to debate the issue on the merits, deliberators eschew resort to coercive pressure and other ulterior methods of forcing agreement, accepting that others are ultimately entitled to come to their own conclusions.

Aiming at persuasive, logical argument: Deliberators try to provide plausible arguments that link together logically, by the standards of informal logic (Eemeren and Grootendorst 2003; Fogelin and Sinnott-Armstrong 2001), to provide rational support for their positions. This norm does not prohibit appeals to emotive speechfor example, as might be used to elicit support for a moral principle. Instead, it requires trying to avoid fallacious arguments, and to stay relevant to the matter at hand.

Aiming at reasonableness: Deliberators attempt, so far as possible, to provide reasons and evidence that can be understood and endorsed by all deliberators.

Aiming at clarity: Deliberators try to be as clear as they can by defining their terms, working with their interlocutor in making distinctions as necessary, and carefully spelling out their argument's logical structure.

While shared deliberation's first four norms set down prescribed actions (deliberators must respect the equal standing of all other deliberators, speak in good faith, genuinely consider alternative viewpoints, and refrain from forcing others into acquiescence), the final three norms only invoke aims. In terms of logic, reasonableness and clarity, it is enough that shared deliberators genuinely attempt to achieve these ideals, and that they do their best to resolve potential problems as they arise. This allows interlocutors with no special expertise to engage 
in the practice. Indeed, while shared deliberation has its roots in philosophical and communications theory, its norms should appear relatively common-sense and intuitive (Schreier et al. 1995). Ideally, readers will recognise instances of its practice from their own lives, when two or more people have done their best to resolve a disagreement or quandary by conscientiously arguing out the issue on the merits - whether over a bottle of wine or in a boardroom, whether in a parliamentary chamber or around a kitchen table.

\section{Basic moral issues in shared deliberation}

Below I marshal several lines of argument to vindicate the ethical—as well as epistemic significance of shared deliberation's norms. But it is worth flagging at the outset that several of these norms align with a laundry list of everyday moral duties. For example, engaging in good faith accords with duties of honesty, as do efforts to avoid misrepresenting one's opponents' arguments. Staying focused on rational persuasion about the argument at hand requires eschewing threats and coercion—obvious deontological wrongs. Indeed, engaging in efforts at persuasion without cleaving to the high standards of shared deliberation can implicate an agent in a host of morally worrying activities, including attempts to subjugate, manipulate, command, coerce, conquer, deceive, exploit and beguile one's interlocutor (Brockriede 1972; Johannesen 1971; Keller and Brown 1968). Shared deliberation's norms also provide a base-line of civility. Wanton, intentional abuse will violate the norms proscribing irrelevance, fallacies (such as ad hominem) and ulterior pressures. Other types of offensive declarations can violate the requirements for equal standing and open-mindedness.

Despite these goods, and the many others I describe below, it cannot be denied that even high-standards argument can prove a morally fraught endeavour. Suppose X and Y are engaged in argument. During their deliberation, X can call into question Y's deepest beliefs, convictions and values, she can evince scepticism about Y's evidence, experience and expertise, and she can critically interrogate Y's reasoning and rationality. While there may 
not be anything intrinsically wrong with these activities, they can nevertheless feel for Y like very personal attacks. They can imply that $\mathrm{Y}$ is foolish, illogical, gullible, uneducated or untrustworthy, or force him into discomfort, frustration, embarrassment and confusion. Deepseated psychological processes in Y-like confirmation bias (including 'selective exposure': Y's desire to only be exposed to evidence congenial to his beliefs), social identity and status, and the internal desire for self-efficacy (driving Y to view himself as capable of making accurate predictions and effective plans) — can push back hard against X's challenges. Y may even have material stakes riding on the outcome. For example, he might be hoping to secure agreement on a collective policy that directly aligns with his projects, contributions and values.

Granted, if X maintains shared deliberation's high standards, this will limit many of these costs. But not all of them. At the very least, the quality of Y's beliefs and reasons are still being interrogated, and this can be a bitter pill to swallow. This concern with rational argument has been known since the dawn of philosophy. Socrates would often carefully explain his dialectical methods and gather consent to them, before drawing his Athenian compatriots into discourse (Plato 1997 (380BC), 457c-58d).

These costs have moral relevance. They heighten the moral need for high quality standards of argument, to at least limit any gratuitous costs to the disputants' wellbeing. At the same time, and somewhat paradoxically, these costs make those very standards difficult to attain. Both X and $\mathrm{Y}$ are continually managing their own instinctive defensiveness, social identities and confirmation biases, and will need to work hard to remain fair and open-minded. 


\section{Shared Deliberation's Epistemic and Cognitive Goods}

Shared deliberation delivers valuable epistemic and cognitive goods. Engaging in shared deliberation, and supporting others' attempts to engage in it, empowers people's attempts to achieve these goods.

By 'epistemic goods', I refer to the acquisition by the deliberators - and by their audience, if applicable — of justified and true beliefs, and the shedding of unjustified and false beliefs. There are good reasons to believe that participating in, and bearing witness to, shared deliberations will tend to increase the accurateness and justifiability of deliberators' beliefs and convictions.

Philosophy has long valorised the potential of argument for improving one's knowledge by opening oneself up for self-refutation (Daniel Cohen 2009, 59; Mill 1859/2003; Plato 1997 (380BC), 457e-58a, 70c). Contemporary argumentation theory and social epistemology has underscored this promise. True, some forms of collective discussion erode epistemic goods, promoting groupthink and exacerbating polarization (Sunstein 2006, 45-78). But in cases where the norms of shared deliberation apply_especially the lynchpin requirement for openmindedness in considering diverse opinions, perspectives and evidence-argument can outperform individual reasoning, including by helping people overcome perennial biases in their thinking (Aikin and Clanton 2010, 411; Correia 2012, 233-35; Sunstein 2006, 80, 201). This link between argumentation norms and epistemic outcomes is no accident. Accounts of deliberative virtues and principles of ideal argumentation are explicitly defined in teleological terms around the collective pursuit of epistemic goods. Virtuous arguers are defined as those who 'propagate truth' and 'are disposed to spread true beliefs around' (Aberdein 2010, 173; Aikin and Clanton 2010; Daniel Cohen 2009). 
'Cognitive goods' constitute valuable mental states and qualities that stretch beyond the strict accuracy of our beliefs (Daniel Cohen 2009, 52-55). Two types are relevant here. First, cognitive goods include habits of mind, intellectual skills and mental predispositions. For example, a person who frequently engages in shared deliberation will tend to acquire the habits, skills and predispositions of critical thinking, awareness of fallibility, openmindedness, intellectual curiosity and reflectiveness - qualities that can be worthwhile in themselves or useful in attaining further goods.

Second, certain cognitive states carry their own value. For example, shared deliberation can deliver improved coherence across one's beliefs and between one's beliefs and values. It can also enhance understanding. Understanding is not factual knowledge itself, but is rather a cognitive relationship to a comprehensive, coherent body of information (Elgin 2007, 35). It includes the capabilities to grasp evidence, theories and ideas, to know how they fit together, how and when they can be applied, what would count as falsifying evidence to them, and to conceive new applications and hypotheses on their basis.

Understanding can be particularly valuable when it allows one to see the world as others do, and to empathically take on their perspectives. But it attains arguably its greatest value when it applies to our own convictions. If a person regularly engages in shared deliberation, she is likely to acquire a strengthened understanding of her own beliefs, including awareness of alternative positions, and what may be said for, and against, her most prized convictions. This is the well-known cognitive benefit of self-education: arguing with $\mathrm{Y}$ can allow $\mathrm{X}$ 's hidden assumptions and incomplete lines of reasoning to be made explicit to her (Walton 1989). As John Stuart Mill (1859/2003, 35) once observed, 'He who knows only his own side of the case knows little of that.' 
As well as exploring matters of truth and falsity, shared deliberation may also deal with practical collective decision-making, such as for developing position-statements, practical policies and group actions. Further cognitive benefits may arise in this context, such as the creation of positions that are deemed justifiable across the group, or incorporate everyone's contributions, or are reasonable to everyone in the group. These changes can also give rise to important shifts in cognitive commitments, such as where a committee member argued against a position, but once it has been carefully discussed and adopted by the group, she is willing to join with the rest of the committee in throwing their weight behind it.

In what follows, I will presume both that shared deliberation does in fact (as a general tendency) provide these types of epistemic and cognitive goods, and moreover that some people intentionally engage in shared deliberation for the purpose of achieving these goods.

Of course, shared deliberation is not a unique route to these goods; they may also be achieved from practices of listening, reading, formal learning, self-reflection, negotiation and so on.

\section{Ethical reasons for pursuing these goods through shared deliberation}

Epistemic goods can acquire moral significance when accurate beliefs are required inputs into immediate moral decision-making. That is, an agent is faced with making a decision, and to arrive at a proper and ethically legitimate outcome they will need to have an accurate (or at least justifiable (Breakey et al. 2015)) understanding of their factual situation, and apply defensible moral principles to that understanding. To the extent deliberation assists the agent in attaining these epistemic and cognitive necessities (viz, accurate empirical beliefs, justifiable moral principles, rational application of principles to fact situations), an agent can have strong moral reason to engage in that practice.

A more sweeping moral significance for epistemic goods arises if knowledge itself, and the self-directed pursuit of that knowledge, constitutes an intrinsically worthy human good. Since 
Socrates first posited that the unexamined life is not worth living, myriad philosophers have lauded the intrinsic goods of knowledge and self-education (Breakey 2012, 155-82). To take just one influential example, John Finnis argued that knowledge serves as a basic value of human existence, and so as a principle of practical reasoning, insofar as we all recognize finding out and pursuing truth and knowledge as sufficient explanations of purposive human activity (Finnis 1980, 61). If that is right, then the pursuit of the objectively best ethical life would constitutively include taking part in actions - including deliberation and dialoguethat achieve these intrinsic goods.

A different way of deriving a general moral significance for epistemic goods draws on Bernard Williams' (2002) argument that the moral virtue of trustworthiness has two elements. Sincerity requires stating what one believes, while accuracy involves the speaker having a factually correct belief in the first place. Only when both elements are in place do we have reasons to take another's beliefs as our own. But accuracy, of course, is simply the epistemic good of holding correct (and not incorrect) beliefs.

In such ways as these, we can work our way from an ethics of belief - that in the first instance directs the internal procedures of rational thought — to an ethics of argument - that directs the interpersonal procedures of rational deliberation (Robinson 2009). In each case, the ethical significance of holding accurate beliefs, and avoiding inaccurate beliefs, flows through to the personal and interpersonal processes that reliably deliver those morally worthy results.

Turning now to cognitive goods: intellectual dispositions and mental conditions can constitute valuable moral goods insofar as they are implicated in ethical virtues. For example, critical thinking, reflectiveness and coherence among an agent's beliefs and values appear in many contemporary accounts of the personal virtue of integrity (Breakey 2016; Graham 
2001). To the extent integrity is a moral virtue, we have moral reason to strive for these cognitive goods. To take another instance, the cognitive virtues of open-mindedness and the ability to understand others' positions work as crucial bulwarks against prejudicial and dismissive reactions to others' views and actions, a potent source of morally worrying intolerance. Argumentation virtues — of the kind found in shared deliberation - can engrain habits of mind that push back against both cold (cognitive) and hot (emotional) biases, rendering us less vulnerable to this source of intolerance (Correia 2012).

Epistemic and cognitive goods can also achieve moral significance when they are being intentionally pursued by someone else (either for personal or moral reasons), and we can altruistically help that person achieve those goals.

The moral significance of these epistemic and cognitive goods provides reason (at least sometimes) to pursue them, and to assist others in pursuing them, through practices like shared deliberation. But does this significance vindicate the stronger proscription that we must always avoid violating the standards of shared deliberation?

There are three ways this strong prohibition might be delivered. The first avenue observes that even though $\mathrm{X}$ might have no obligation to positively help $\mathrm{Y}$ attain epistemic and cognitive goods, she may nevertheless have a duty not to interfere with Y's attempts to fulfil these goals. Engaging him in argument, and then misleading and misrepresenting him, may constitute wrongful interference.

The second avenue stresses that poor argument-practices, like poor belief-revision practices, are not merely activities where we fail to personally attain epistemic and cognitive goods. Instead, they actively degrade those goods. Low standards argument encourages epistemic error and cognitive pitfalls like groupthink, close-mindedness, polarization and bias. If 
developing epistemic and cognitive goods in ourselves and others has moral significance, then we must avoid practices that degrade those goods and the faculties that deliver them.

The third avenue posits that, if knowledge is an intrinsic value, then we are not merely called upon to 'maximise it', but rather to - as Finnis $(1980,96)$ puts it - to participate in it. This involves not only taking positive actions to realize it, but also a strict prohibition on damaging the value for oneself and others.

In these three ways, we can move from the moral significance of epistemic and cognitive goods to reasons to cleave to high standards of rational deliberation.

\section{Respect for others' rationality}

This section argues that engaging in, and respecting the norms of, shared deliberation respects others' rationality. It then argues that, in so doing, it respects others as persons.

Section 2 observed that when someone disagrees with us, and challenges our thinking, it can easily feel as if they are disrespecting us. But borrowing Oscar Wilde, we might say that there is only one thing in the world worse than being argued with, and that is not being argued with. For there are several important ways in which a deliberator, holding to shared deliberation's norms, shows respect for her opponent. First, attempting to persuade another person through reason, logical argument and evidence, and by exploring and critiquing their position on these bases, acknowledges that one's interlocutor is a rational being, willing and able to make decisions and form beliefs on an intelligent, reasoned basis. Second, by limiting oneself to the use of rational persuasion, and foregoing any ulterior means in situations where one fails to rationally persuade, one acknowledges that one's interlocutor is ultimately entitled to their own view: it is their mind and their thinking that rightly retains regency over their beliefs and decisions (Keller and Brown 1968, 77; White 1983, 870). Third, by allowing the interlocutor to critique one's own view, and by opening the possibility that they will 
successfully answer one's critical interrogations, we recognise that as a rational being they may well possess reasons, evidence, experiences, unique perspectives and lines of thought that can help us think and make up our own minds. Fourth, by accepting the reciprocity and mutuality of shared deliberation's norms (especially its norm of mutual respect and equal standing), we treat the person in important respects as our rational equal: we do not arrogate a privileged position in the argument, nor do we patronise their beliefs. Indeed, in some respects we employ the strongest form of mutuality and equality imaginable: we treat their beliefs as we do our own, questioning them, clarifying them, and affirming them when they are found to be justified.

Respecting another's rationality constitutes an important way of respecting the person as such. True, human beings are more than just their rationality. Yet the capacity and use of reason remains a quintessential part of many major accounts of personhood (Seigel 2005), and constitutes a key foundation for thinking human beings should be entitled to run their own lives. Being 'endowed with reason' is lauded in the very first article of the Universal Declaration of Human Rights, in support of its ringing declaration that humans are born free and equal in dignity and rights (General-Assembly 1948). This lofty panegyric aligns with common-sense and lived experience. Attempts at excluding people from the moral community routinely attack their rationality, arguing that they cannot be reasoned with, that they understand only force or brute conditioning, or that they are manipulated and gulled by larger (usually sinister) social forces.

The relationship between rationality and moral respect takes centre stage in Kant's ethics. As Paul Formosa argues in his recent exploration of Kant's principle of humanity: 'The empirical conditions under which human beings can acquire, sustain, exercise and develop their rational capacities are of core moral importance...' $(2017,79)$. Given that the respect owed to others' rational capacities is owed to all parts of their rational nature (including 
moral, prudential and theoretical components), a practice like shared deliberation, offering valuable epistemic and cognitive goods, and helping overcome perennial vulnerabilities and biases in our rational capacities, possesses intrinsic moral significance. Some of shared deliberation's norms will stand as perfect Kantian duties not to use ourselves or others as a mere means, in particular by degrading our or others' rational capabilities. For example, actions like trickery, manipulation and avoidable misrepresentation in argument may express disrespect for, and even subvert, demoralise and confuse, an interlocutor's rational capacities, while the wilful refusal to seriously consider others' critical arguments may amount to degrading our own rational capacities. Similarly, respect for our and others' rational capacities will prohibit us from treating other's reasoned arguments with contempt or ridicule, or engaging in wanton fault-finding: Kant explicitly inveighed against such wrongs (1996, 6:463-68). But it is perhaps in the Kantian imperfect duty to treat oneself and others as ends in themselves where shared deliberation's positive moral significance lies. This duty commands us to develop and cultivate our rational capacities, and to respond appropriately to others' efforts to do the same. Effectively, we have an imperfect duty to aid in the selfperfection of others' rational capacities when they themselves are attempting this. Of course, one does not have to be a dyed-in-the-wool Kantian to appreciate the importance of respecting this pursuit. Similar ideas emerge in Keller and Brown's (1968) ethic of communication, which requires responding to the mutual control (and vulnerability) of participants, so as to respect the freedom of each to develop their own individual potential.

If these links between respect for rationality and respect for persons are correct, then if someone is trying to improve their rational capacities by engaging in shared deliberation (e.g., to better their understanding, reasoning, or knowledge), then we have moral reason to positively support them in that end — and decisive moral reasons not to interfere with or degrade their rational capabilities for our own self-interested ends. Ultimately, respecting 
others' rationality matters morally, and shared deliberation's norm offer a direct way of doing just this.

\section{Joint action and collective achievement}

The previous sections argued that we have reasons to morally value both our own and other's epistemic and cognitive goods, and to respect our own and others' rational capabilities. Yet many of these arguments would apply as much to unilateral and unidirectional actions (of writing, reading, lecturing, learning and reflecting) as much as to interactions (like argument and conversation). But much of the special moral significance of deliberation lies in its nature as a joint action, a collective achievement (Schreier et al. 1995).

There is a thin deontological point here about consensual interaction that we can put in Kantian terms: because shared deliberation is a collective activity-especially (but not only) if it is done in real time, and face-to-face-if X engages in this form of interaction with $\mathrm{Y}$, but then violates its norms for some discretionary end that $\mathrm{Y}$ does not share, this may amount to $\mathrm{X}$ treating $\mathrm{Y}$ as a mere means (Formosa 2017, 92). The interaction initially appeared to be consensual, but ultimately it was not.

But there is a deeper, richer point here too, that I want to at least gesture towards as best I can, lest what is most special about deliberation lie unmentioned. Much of modern ethics proscribes wrongs and harms - the 'lows' of human life. But some ethics, at least, directs us to the 'highs' - the most meaningful pinnacles of a life-well-lived. Shared deliberation can attain such heights. For it is not merely that $\mathrm{X}$ and $\mathrm{Y}$, as individuals, have each benefited, and each benefited the other, as it would if $\mathrm{X}$ beneficently provided charity to $\mathrm{Y}$, or $\mathrm{Y}$ respected $\mathrm{X}$ 's rights by leaving her alone to worship her chosen religion. Instead, in shared deliberation the group $X+Y$ has been created, and has jointly delivered benefits to $\mathrm{X}$ and $\mathrm{Y}$. In deliberation, it is both the interlocutors doing it together, and what they each get out of it is a 
function of what they collectively put into it. For the participants, there is a greater sense of inclusiveness, equality and solidarity than is offered by other more unidirectional or hierarchical modes of learning (e.g., lecturer-student; expert-layperson).

To explore the ethical significance of this collective activity, let's consider a close relative of it. Richard Johannesen (1971) builds on the work of philosophers like Martin Buber, psychotherapists, and communication theorists (including Keller and Brown (1968)), to develop the ideal of communication-as-dialogue. This activity has much in common with shared deliberation: its core virtues include mutuality, open-heartedness, directness, honesty, nonmanipulative intention, taking others' views seriously, and prohibitions on ego- or statusbolstering actions. However, in focusing on personal encounter and pro-social outcomes, communication-as-dialogue prioritises respectful understanding, genuine recognition and empathic appreciation of another's perspective. The goal is to fully understand the other's perspective, and to affirm one's unconditional positive regard for them. True, argument is possible. Johannesen's $(1971,380)$ ideal does not prohibit reasoned disagreement and rational persuasion. But the priority remains the authentic recognition of the other and their views, rather than loyalty 'to rationality or cosmic truth' (Keller and Brown 1968, 73). The socio-moral goods that Johannesen's research suggests arise from communication-asdialogue are substantial:

Each person in a dialogic relation is accepted for what he is as a unique individual. One becomes totally aware of the other rather than functioning as an observer or onlooker. The essential movement in dialogue is turning toward, outgoing to, and reaching for the other. $(1971,375)$ 
Even though the mutuality required in communication inevitably involves mutual control, 'the mutual control is of a sort built on a positive ethic: to bring to their finest fulfillment the purposes of each party to the communicative act' (Keller and Brown 1968, 79).

I think many readers will appreciate the moral specialness of this interaction. We noted in Section 2 that even high standards argument can be confronting and upsetting. By prioritizing understanding and recognition, communication-as-dialogue avoids such potentially abrasive interactions. Clearly, there are times when the morally best thing to do for a person would be to ease up on critical interrogation and instead to prioritise genuine listening and authentic perspective-taking.

Yet— that much admitted-I think we should resist thinking this explicit concern with prosocial goods means that communication-as-dialogue is strictly more ethical than shared deliberation. For shared deliberation can deliver this same communication of genuine recognition, meaning and respect. Indeed, while it can be less warm, empathic and affirming, the interaction shared deliberation offers can be deeper and more intimate. Consistent with its psychotherapeutic sources, communication-as-dialogue is more unilateral and one-way: it is about $\mathrm{X}$ coming to truly understand and recognise $\mathrm{Y}$. But shared deliberation is about $\mathrm{X}$ and Y creating something together and doing so in a way that allows great vulnerability in the inter-penetration of the participants' ideas.

Consider first shared deliberation's quality of joint construction: Because the shared deliberation was an intentional collective activity, the results are a shared achievement that reflects the participants' input, values and perspectives — and, often, their intelligence, evidence, experience and information. Constructing the collective good requires strong commitment to the shared practice and the over-arching purpose, in the face of what are often strong reasons to defect (defensiveness, status, 'winning'). Daniel Cohen and George Miller 
(2016) flesh out this unique collectivity through their idea of cognitive compathy, understood (as an analogue to empathy), as the state of two or more people sharing a cognitive state - not because one has copied it from the other, but because, through their collective argument, they have constructed shared knowledge, understanding and meaning. Cohen and Miller (2016, $451,55)$ draw analogies to other similarly collective pursuits, such as jazz musicians improvising together.

Consider now shared deliberation's qualities of mutuality and vulnerability. An interaction like communication-as-dialogue can seem more caring because $\mathrm{X}$ grants respectful protection to $\mathrm{Y}^{\prime}$ 's convictions. But communication-as-dialogue, like shared deliberation, prizes equality and reciprocity between the participants. For this reason, the protection $\mathrm{X}$ grants to $\mathrm{Y}$ 's beliefs is necessarily one that keeps X's beliefs protected from Y. Reciprocity means that any safety rendered to one's interlocutor's thoughts is at the same time a prohibitive barrier guarding one's own thoughts. As such, even as shared deliberation allows X greater scope into Y's mind, so too — though reciprocity—does $\mathrm{X}$ open her mind to Y's equivalent entry. In so doing, shared deliberation requires a deliberator to render the type of questions of her interlocutor's beliefs and values that, if answered well, imply that she herself might have strong reasons to accept them as valid, justified and true and so to take them as her own. And, all the while, she is opening her own views, arguments and ideas up to the like examination of her interlocutor, trusting in him to help clarify and improve the quality of her own thoughts. Each voluntarily opens their minds, not merely for recognition, but for something potentially far more unsettling, challenging and profound: change. They lay bare their ideas and convictions for critique, and do so in a context where they must listen to that critique fairly, foregoing other self-defensive methods (shutting down the discussion, questioning their critic's integrity and standing, shifting to rhetoric, etc.). They cannot say, 'Who asked 
you?' or, 'Who cares what you think anyway?' Shared deliberation requires them to ask, and to care.

Shared deliberation turns out to be a peculiarly delicate interaction, characterized by deep vulnerability. Small wonder, with this reciprocal openness and mutual exploration, that the language of love and sexuality might be invoked to capture the curious cocktail of vulnerability, equality, collectivity, intimacy, and authentic recognition of self and other that shared deliberation can, at its pinnacle, achieve (Brockriede 1972). If two minds can entangle and grow together, then perhaps they do it through inter-penetrated thoughts, the vulnerability of genuine revelation and the thrill of recognition, and the collective construction of something truly shared. They do it, that is, in interactions like shared deliberation.

The point here is not that we should expect every argument, with every interlocutor, to achieve these heady heights. It is, rather, that we would do well ethically to be open to the possibility of this meaningful encounter and special part of our shared humanity. And in a more everyday sense, we should be aware that sometimes, for some people, argument will approach these delicate areas, where they reveal intimate and vulnerable parts of themselves, and wonder whether we would like to share with them in the construction of something new.

\section{Can't we at least talk about this? Consensus and conflict-resolution}

Shared deliberation's final source of ethical significance lies in the possibility of achieving consensus or at least conflict-resolution between the deliberating parties. To be sure, shared deliberation is not the only_nor necessarily the most likely_candidate for achieving consensus. Sometimes, negotiation, voting, compromise and bargaining will be more fruitful practices. But shared deliberation has an important role alongside these other practices, for sometimes the most sustainable agreement will be the one where minds are genuinely changed. 
In aiming to resolve disagreements on the merits of the issue, shared deliberation can lead to practical consensus in three ways.

First, consensus can occur directly in cases where the deliberation leads to successful resolution of the disagreement. Through their deliberation, and the sharing of arguments and experiences, the interlocutors rationally converge on a position.

Second, a final agreement can sometimes be secured when the shared deliberation leads to the development of a position that — while it may not actually be held by all (or any) of the deliberators - nevertheless represents a position that they each see as justifiable, or at least as not unreasonable. Their ultimate beliefs may not change, but they shift their cognitive commitments in line with the group's position.

Third, because (as we have seen) following the norms of shared deliberation involves treating others inclusively, beneficently and respectfully, deliberators may feel that the fact that there was an inclusive and informed discussion, in which different participants' positions were taken seriously and sheer power was not allowed to dominate, gives them reason to accept a resulting policy or position, at least for the time being.

All these types of consensus and conflict-resolution outcomes can be ethically important. Small groups (partners in business, sporting teams, artistic ensembles, civil society organizations, parents and spouses) often need to make decisions about actions, rules, goals or policies going forward. ${ }^{4}$ Without consensus, subsequent decisions and actions implicate serious questions about authority, hierarchy, legitimacy and coercion. There may also be questions about the effectiveness of subsequent policies if they do not secure widespread

\footnotetext{
${ }^{4}$ Recall we are only concerned here with the creation of consensus across the deliberators themselves, bracketing any questions about larger political legitimacy or civic virtue.
} 
buy-in from the actors involved. If consensus amongst the actors and stakeholders can be reached in a non-coercive way, then the subsequent joint actions are much more likely to be morally legitimate and effective. For this reason, the quest for consensus, and efforts to genuinely pursue it through the best available means, acquire moral loading. In these cases, shared deliberation serves as an instrumental good (as a tool for achieving or facilitating consensus). But the moral priority of this larger purpose transmits its significance to the practice that promises to achieve it, and prohibits activities that would derail or frustrate it.

\section{Facing reality: a continuum of argument-practices}

If the foregoing arguments are on the right track, then shared deliberation's moral virtues are many, and we all have strong reasons to respect its norms. But how may those virtues and norms be pursued in a non-ideal world - one where people often engage in argument for very different reasons (not at all related to truth and consensus), and with very different ethical and epistemic standards?

To explore this question, this section sketches an illustrative continuum of argumentpractices, ordered in terms of the demandingness of their standards. ${ }^{5}$ Figure One places different argument-practices on a continuum of ethical and epistemic standards. Its categorizations are neither strict nor comprehensive, and a given practice might lie in the grey area between two categories, or slide between the categories as its standards shift over time, perhaps increasing in ethical care as each interlocutor senses the respect and good faith of the

\footnotetext{
${ }^{5}$ Various theorists have previously suggested that argument-practices could be situated on a continuum of higher- and lower-ethical standards. See, e.g., Crawford 2009; Johannesen 1971. Crawford's taxonomy extends into coercive and non-argumentative terrain.
} 
other, or deteriorating as each retaliate to the other's incursions in a tit-for-tat race to the bottom.
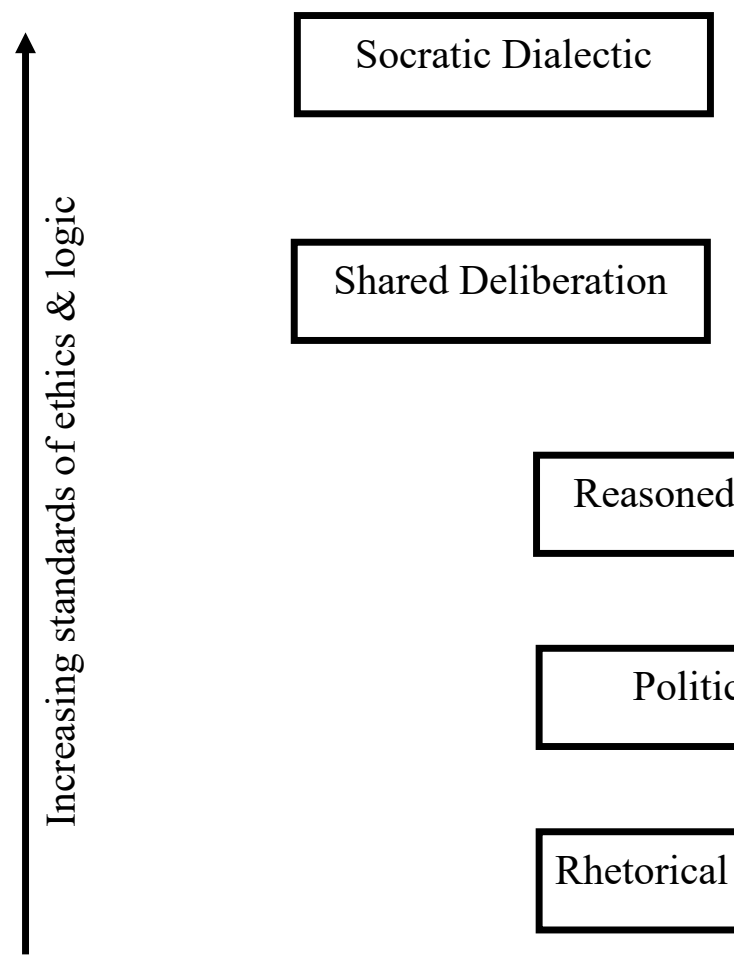

Discourse Ethics

Reasoned Discourse

Communication-as-Dialogue

Rhetorical Propaganda

Figure One: Different Argument-Practices

Following Section 6's discussion, Figure 1 places communication-as-dialogue level with shared deliberation. Some argument practices could have higher standards. 'Socratic dialectic' might require that deliberators actually display high standards of logic, clarity and reasonableness, rather than merely being required to pursue those standards to the best of their ability. On a different tack, 'discourse ethics' would extend the inclusivity and comprehensiveness of the shared deliberations until they began to deliver the civic goods of deliberative democracy and political legitimacy.

Turning to lower standards, we might envisage 'reasoned discourse' as a more common argument practice achieved by fair-minded commentators. Reasoned discourse would include 
many of shared deliberation's norms, aiming for persuasive, clear and logical argument, capable of appealing to reasonable and non-partisan audiences. Yet it avoids shared deliberation's most demanding requirements, such as for genuine open-mindednessincluding charitably understanding one's opponents, admitting ignorance or error, and even (at the limit) of actually and publicly changing one's mind. Adhering to these demands requires considerable discipline and engrained virtue, and often involves personal and social costs, such as a loss in perceived authority or failure of loyalty to one's 'side'. But even without these requirements a less-than-ideal, but nevertheless significant dialogic activity can unfold. Participants in, and witnesses to both sides of, a reasoned discourse will become informed about the key arguments on each side of the dispute, and the main responses to those arguments.

Even lower standards are possible. Indeed, in the world in which we live, much discourseespecially socio-political debate—-has little to do with respectful, rational argument. Some discussants aim simply to raise awareness and dramatise important issues, while other speakers focus on energizing like-minded allies and 'winning' the debate to help secure desired results (such as an election result that may carry its own moral importance). Moreover, the arguments that colonise social media posts, twitter feeds, talkback radio, satirical news programs and 'comments' sections in online newspapers and blogs are usually rife with invective, exaggeration, points-scoring and the active pursuit of outrage.

Figure 1 lists two illustrative low-standards argument-practices. 'Political spin' is argument designed to win at all costs. In it, arguers try to avoid being caught in obvious fabrications or clumsy inconsistencies, but often revel in straw person and ad hominem fallacies. Political spin spurns open-mindedness, and may even avoid clarity and good faith. Indeed, deliberate obfuscation and dissimulating slipperiness in the face of tough questions constitute unspoken virtues of this practice. 
At a lower standard again lies 'rhetorical propaganda', which is largely a pretence at argument. 'Reasons' are given and linked with 'conclusions', to provide a veneer of argumentative legitimacy, but in truth there is no serious attempt at ensuring logic, clarity, consistency or reasonableness, much less open-mindedness and mutual respect. We have what Johannesen $(1971,377)$, following Buber, would term 'pseudo-dialogue', or monologue disguised as dialogue.

Neither political spin nor rhetorical propaganda offer substantial epistemic or cognitive goods. They do not force an interlocutor to clarify or hone their own thinking, they do not challenge convictions with new ideas or evidence, and they do not facilitate genuine understanding of alternative positions. Yet note that both political spin and rhetorical propaganda remain argument-practices (or at least pseudo-argument-practices) in the sense of the speaker purporting to provide persuasive reasons for a listener to rationally accept a factual claim, policy choice or normative principle. Lower standards practices, such as of wanton abuse, threat and mockery, dispense with even the pretence of argument (and so do not appear in Figure One).

\section{Practices, not venues}

It is easy to imagine contexts, arrangements and venues where different argument-practices are more likely. We might envisage Socratic dialectic between experienced scholars at an academic conference, shared deliberation between two colleagues conscientiously thinking through a moral dilemma, reasoned discourse in the work of quality journalistic commentators, political spin from a politician managing an unfolding scandal, and rhetorical propaganda in partisan preaching to the converted. No doubt, context influences the standards of argumentation. 
Yet context does not determine practice. Just as it is possible for academics to descend into petty cavilling, we should not be too quick to write off the prospects for high-standards argument in the most unlikely places. Indeed, even in the most improbable settings, such as hard-nosed and high-stakes international negotiations, discussants may apprehend the most demanding of shared deliberation's virtues: the willingness to change one's mind under the force of the better argument. As Thomas Risse $(2000,9)$ observes, citing actual and worldshaping historical instances, 'argumentative processes might well begin as purely rhetorical exchanges but often evolve toward true reasoning'. As such, glib cynicism should not prevent us from recognizing the stirrings of high standards argument whenever and wherever they arise.

\section{Ethical obligation in the face of this continuum}

Suppose $\mathrm{X}$ enters a disputation in the hopes of an edifying argument, only to find her interlocutor gleefully resorting to political spin and rhetorical propaganda. Usually, X will have the option of excusing herself from the debate, and this will often be a sensible course of action. But suppose she decides to remain. If the arguments outlined above are correct, does X still have strong moral reasons to cleave to high standards of deliberation? ${ }^{6}$

It is easy to suppose the answer is 'no', as many of the most powerful reasons for X's high standards dissolve in the face of Y's wanton disrespect. There are less epistemic and cognitive goods (from Sect. 3) on offer to either disputant, or the audience (if any), meaning that the failure to pursue these goods is less serious. It is hard for X to display respect for Y's rationality (from Sect.4), when $\mathrm{Y}$ is not even trying to be rational, and it cannot be said that $\mathrm{X}$ is interfering with Y's pursuit of valuable goods, or engaging non-consensually with Y, or

\footnotetext{
${ }^{6}$ Recall we are bracketing cases with explicit rules and prior agreements about argument norms.
} 
failing to reciprocate $\mathrm{Y}$, when $\mathrm{Y}$ himself has set the terms of the interaction with his poor behaviour. Finally, there is little sense of a joint collective achievement (Sect. 6) and much less chance of developing any sort of practical consensus (Sect.7).

Despite all this, I think a surprisingly strong case can be made for the moral obligation to hold firm to shared deliberation's norms, even in the face of poor standards by one's interlocuter.

First, continued respectful argument by $\mathrm{X}$ will help communicate to $\mathrm{Y}$ that a higher standard of argument is available. For genuine deliberation to arise out of rhetoric, someone has to move first - and successfully raising the tone may bring online more epistemic, cognitive and consensual goods.

Second, there likely will be at least some epistemic and cognitive goods on offer. Even if $\mathrm{Y}$ is wilfully refusing to learn about X's arguments, $\mathrm{X}$ may still learn about Y's reasons for his position, and the main flaws he perceives in X's position. So too may an audience- though they may also be listening attentively and fruitfully to $\mathrm{X}$, and gaining understanding of her position. But the deeper concern is that if $\mathrm{X}$ decides to cast off the shackles of proper argument this may impact upon her own epistemic goods and cognitive habits; she may open her mind to hasty generalization, shoddy logic and reckless caricature as she beats $\mathrm{X}$ at his own game. There are thus genuine epistemic and cognitive costs to her retaliation.

Third, many of X's Kantian obligations remain relevant. Even if Y has poor standards of argument, this doesn't license $\mathrm{X}$ to further degrade $\mathrm{Y}$ 's rationality by misleading, confusing and demoralizing his reasoning processes and practices. As well, basic standards of honesty and consent still inhere; $\mathrm{X}$ should not wilfully misrepresent $\mathrm{Y}$ 's position, and if $\mathrm{X}$ and $\mathrm{Y}$ need to come to a decision about a collective action, then Y's substandard behaviour is no excuse for X to subsequently manipulate or bamboozle him into agreement. 
Further reasons come to light once we remember low standards argument practices are effectively pseudo arguments. Because $\mathrm{Y}$ maintains the pretence of argument, his position is still vulnerable to rational refutation. In many sports and games, one side's ability to cheat renders the other side effectively powerless - it becomes pointless to play by the rules. But in argument, X's high standards can still carry the day—not despite Y's substandard behaviour, but because of it. Y's low-standards argument is characterized by, and so vulnerable to the demonstration of, logical errors and fallacious premises.

More worrying again, if $\mathrm{X}$ lowers her standards, she joins $\mathrm{Y}$ in his hypocrisy-in his pretence that he is still in the business of rational argument, when he is actually making a mockery of it. In so doing, I submit, $\mathrm{X}$ fails to take reason and rationality seriously, and to acknowledge their intrinsic worth. She no longer, as Finnis would put it, participates in the values of knowledge and truth.

There is one final consideration worth bearing in mind. In outlining the scenario above I simply asserted that $\mathrm{Y}$ was wantonly disregarding proper standards of argument. But in any real-world case, $\mathrm{X}$ herself must make a judgment call on whether this is occurring. And this should give X serious pause, because it can be extremely hard to objectively judge the deliberative standards of one's interlocutor during a heated dispute. After all, sometimes Y's failure to live up to deliberative standards will be an honest failure. For example, if Y appears to violate the principle of charity, this may be an honest misinterpretation of X's position, rather than an intentional mischaracterisation. Alternatively, $\mathrm{X}$ might mistakenly think $\mathrm{Y}$ has dealt illicitly with her, when in fact his critique is entirely valid, but she does not want to recognise this validity. For example, $\mathrm{X}$ thinks $\mathrm{Y}$ is caricaturing her position when he links it to an absurd conclusion — but Y's position may be genuinely vulnerable to a reductio ad absurdum. It would not be surprising for X to instinctively see the worst in Y's arguments and intentions. After all, X can have a lot at stake in her argument, and Y's strongly-worded 
counter-arguments can easily be interpreted as objectionable. As Mill (1859/2003, 50-51) noted:

I think experience testifies that this offence is given whenever the attack is telling and powerful, and that every opponent who pushes them hard, and whom they find difficult to answer, appears to them, if he shows any strong feeling on the subject, an intemperate opponent.

Finally, even if Y is deliberately employing low-standards, it is possible he believes he is legitimately responding to an earlier intervention by $\mathrm{X}$ which he (perhaps accurately, perhaps inaccurately) perceived as failing to live up to appropriate standards.

There are thus multiple ways that X might misread Y's arguments, and mistakenly perceive wrongdoing. If $\mathrm{X}$ retains high standards and rationally interrogates $\mathrm{Y}$ 's suspect arguments, then potential misunderstandings may be resolved. But if she retaliates by casting aside the norms of shared deliberation, X may herself commit the serious wrong of deliberately violating argument standards against an interlocuter trying in good faith to uphold thembringing into play the full gamut of moral concerns raised in this article, including interference, non-consensual interaction and the wilful degrading of epistemic and cognitive goods.

Ultimately, when a deliberator is faced with an interlocuter's seemingly deliberate or reckless violation of deliberative standards, it may be understandable — and even excusable — to react defensively, and to fight fire with fire. But if the above arguments are sound, the ethically correct course of action (if it is not to excuse oneself entirely from the argument) is to try one's best to maintain disciplined respect for the norms of shared deliberation. 


\section{Conclusion}

I hope to have vindicated the intuitions of moral loading with which we began. Spurning the norms of shared deliberation can violate basic norms of honesty, can strip intrinsically and instrumentally valuable epistemic and cognitive goods from others, can stymie our own capabilities for empathy, open-mindedness, trustworthiness, understanding and integrity, can disrespect others' rationality, and can exploit others' vulnerabilities as they open themselves for joint actions and collective decision-making. Ultimately, deliberative norms are not only epistemic, but ethical. ${ }^{7}$

\section{References}

Aberdein, A. 2010. Virtue in argument. Argumentation 24: 165-79.

Aikin, S.F. and J.C. Clanton. 2010. Developing group-deliberative virtues. Journal of Applied Philosophy 27, no 4: 409-24.

Bentley, R. 2005. Political disagreement and socratic civic competence. Political Studies 53: 516-36.

Breakey, H. 2012. Intellectual liberty: Natural rights and intellectual property. Surrey: Ashgate.

Breakey, H. 2016. Compromise despite conviction: Curbing integrity's moral dangers. Journal of Value Inquiry 50, no 3: 613-29.

\footnotetext{
${ }^{7}$ Thanks for helpful comments go to Paul Formosa and an anonymous reviewer, as well as to participants at the University of Queensland philosophy seminar series and at the Annual Conference of the Australian Association for Professional and Applied Ethics.
} 
Breakey, H., R.V. Winsen and S. Dekker. 2015. 'Loss of situation awareness' by medical staff: Reflecting on the moral and legal status of a psychological object. Journal of Law and Medicine 22: 632-37.

Brockriede, W. 1972. Arguers as lovers. Philosophy \& Rhetoric 5, no 1: 1-11.

Cadman, T. 2011. Quality and legitimacy of global governance. London: Palgrave Macmillan.

Cohen, D. 2009. Keeping an open mind and having a sense of proportion as virtues in argumentation. Cogency 1, no 2: 49-64.

Cohen, D. and G. Miller. 2016. What virtue argumentation theory misses: The case of compathetic argumentation. Topoi 35: 451-60.

Cohen, J. 2004. Minimalism about human rights: The most we can hope for? The Journal of Political Philosophy 12, no 2: 190-213.

Correia, V. 2012. The ethics of argumentation. Informal Logic 32, no 2: 222-41.

Crawford, N. 2009. Homo politicus and argument (nearly) all the way down: Persuasion in politics. Perspectives on Politics 7, no 1: 103-24.

Eemeren, F.V. and R. Grootendorst. 2003. A systematic theory of argumentation. Cambridge: Cambridge University Press.

Elgin, C. 2007. Understanding and the facts. Philosophical Studies 132: 33-42.

Finnis, J. 1980. Natural law and natural rights. Oxford: Clarendon.

Fogelin, R. and W. Sinnott-Armstrong. 2001. Understanding arguments: An introduction to informal logic. 6th ed. Orlando: Harcourt College Publishers.

Formosa, P. 2017. Kantian ethics, dignity and perfection. Cambridge: Cambridge University Press.

General-Assembly, U.N. 1948. Universal declaration of human rights.

Graham, J.L. 2001. Does integrity require moral goodness? Ratio XIV: 234-51. 
Johannesen, R. 1971. The emerging concept of communication as dialogue. The Quarterly Journal of Speech 57, no 4: 373-82.

Kant, I. 1996. The metaphysics of morals. In Practical philosophy, ed. Gregor, MJ. Cambridge: Cambridge University Press.

Keller, P. and C. Brown. 1968. An interpersonal ethic for communication. The Journal of Communication 18: 73-81.

Mill, J.S. 1859/2003. Ed. Rapaport, E. On liberty. Cambridge: Hackett. (Orig. pub. 1859.)

Plato. 1997 (380BC). Gorgias. In Plato: Complete works, ed. Cooper, JM, 791-869. Cambridge: Hackett.

Rawls, J. 2005. The idea of public reason revisited. In Political liberalism, 440-90. New York: Columbia University Press. (Orig. pub. 1997).

Risse, T. 2000. 'Let's argue!' Communicative action in world politics. International Organization 54, no 1: 1-39.

Robinson, S. 2009. Dialogue and disputation: Towards an ethics of academic discourse. In 4th Asia Pacific Conference on Educational Integrity (4APCEI). Wollongong NSW Australia.

Rorty, A. 2011. Aristotle on the virtues of rhetoric. The Review of Metaphysics 64, no 4: 71533.

Schreier, M., N. Groeben and U. Christmann. 1995. 'That's not fair!' Argumentational integrity as an ethics of argumentative communication. Argumentation 9: 267-89.

Seigel, J.E. 2005. The idea of the self: Thought and experience in western europe since the seventeenth century. New York: Cambridge University Press.

Sunstein, C. 2006. Infotopia. New York: OUP.

Thorson, J.K. 2016. Thick, thin, and becoming a virtuous arguer. Topoi 35: 359-66. 
Umphres, W.P. 2018. Beyond good reasons: Solidarity, open texture, and the ethics of deliberation. Constellations: 1-14.

Walton, D.N. 1989. Dialogue theory for critical thinking. Argumentation 3: 169-84.

White, J.B. 1983. The ethics of argument: Plato's Gorgias and the modern lawyer. University of Chicago Law Review 50: 849.

Williams, B. 2002. Truth \& truthfulness: An essay in genealogy. Princeton, N.J.: Princeton University Press. 